\title{
Quantifying the landscape influence on plant invasions in Mediterranean coastal habitats
}

\author{
Pablo González-Moreno • Joan Pino • \\ David Carreras · Corina Basnou • \\ Iván Fernández-Rebollar • Montserrat Vilà
}

last two groups of variables were calculated at five different spatial extents. Landscape composition was by far the most important group of variables associated with non-native species richness. Natural areas close to diverse and urban landscapes had a high number of nonnative species while surrounding agricultural areas could buffer this effect. Regional human influence was also strongly associated with non-native species richness while habitat type was the least important factor. Differences in sensitivity of landscape variables across spatial extents proved relevant, with $100 \mathrm{~m}$ being the most influential extent for most variables. These results suggest that landscape characteristics should be considered for performing explicit spatial risk analyses of plant invasions. Consequently, the management of invaded habitats should focus not only at the stand scale but also at the highly influential neighbouring landscape. Prior to incorporate landscape characteristics into management decisions, sensitivity analyses should be taken into account to avoid inconsistent variables.

Keywords Non-native plants - Level of invasion . Land-use and land-cover change - Landscape configuration - Spatial heterogeneity · Species richness $\cdot$ Urban area

\section{Introduction}

There is increasing interest in disentangling local and geographic effects on the distribution and abundance
Observatori Socioambiental de Menorca (OBSAM-IME),

Camí des Castell 28, 07702 Maó, Spain
Electronic supplementary material The online version of this article (doi:10.1007/s10980-013-9857-1) contains

P. González-Moreno $(\bowtie) \cdot$ M. Vilà

Investigaciones Científicas (EBD-CSIC), Av. Américo Vespucio S/N, Isla de la Cartuja, 41092 Sevilla, Spain

J. Pino $\cdot$ C. Basnou

Centre for Ecological Research and Forestry Applications (CREAF), Universitat Autònoma de Barcelona,

08193 Bellaterra, Catalonia, Spain

D. Carreras · I. Fernández-Rebollar

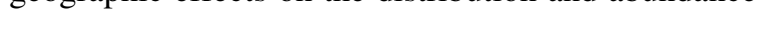


of non-native plant invasions (Chytrý et al. 2008a; Marini et al. 2009; Catford et al. 2011). Although significant advances have been made, several aspects remain largely unexplored. For instance, we still do not have a thorough understanding of the effects of patch and landscape characteristics (Vilà and Ibáñez 2011) compared to those of the regional degree of human influence or habitat type (Chytrý et al. 2008a; Catford et al. 2011). Regions with heavy human influence have an overall increase in the probability of non-native plant arrival and establishment (Pyšek et al. 2010; Kueffer et al. 2010) that can be driven among other causes to a high use of ornamental species for gardening and restoration. Furthermore, within particular regions, the level of plant invasion among habitat types has proven to be different with water and nutrient rich habitats being more invaded than dry and stressful habitats (Chytrý et al. 2008b).

The main landscape characteristics associated with invasion are related to human land-cover such as builtup areas or transportation infrastructures edges (Sullivan et al. 2005; Gassó et al. 2009; Gavier-Pizarro et al. 2010). These human-altered areas are a common reservoir of non-native species (Ohlemüller et al. 2006; Gavier-Pizarro et al. 2010) that can enhance the non-native propagule pressure on nearby natural areas. Except landscape composition (i.e. distribution of landcover categories), the analysis of other landscape characteristics related to its configuration (e.g. habitat fragmentation) and habitat patch geometry (e.g. size and shape) have received less attention (Deutschewitz et al. 2003; Kumar et al. 2006). The exploration of these variables could give new insights into secondary invasions from land-use areas other than urban (Vilà and Ibáñez 2011).

Another aspect that still requires attention is the spatial extent (i.e. buffer area from the focal sampling unit) at which landscape characteristics influence local invasions (Kumar et al. 2006). It is well known that the influence of landscape characteristics on many ecological processes is dependent on the extent. For instance, the effect of habitat fragmentation on plant pollination and predation varies depending on the size of the landscape under consideration (Steffan-Dewenter et al. 2001). In this case, the influence of habitat fragmentation on pollination occurred at an extent of up to $1,000 \mathrm{~m}$ from the sampled patch, while the influence on predation took place at a larger extent $(2,500 \mathrm{~m})$. The few studies exploring the effect of extent on plant invasions point to maximum influence at smaller extents ( $\sim 250 \mathrm{~m})$ (Kumar et al. 2006; Bartuszevige et al. 2006).

In this paper, we first explore the influence of patch and landscape characteristics on non-native species richness at different spatial extents and then we analyse their importance compared to the regional degree of human influence and habitat type controlling for climatic variability. The study was conducted in three coastal regions in Spain differing in their degree of human influence. Mediterranean coastal areas have a large number of habitats of high conservation concern which have been included in the Habitats Directive 92/43/EEC of the European Council (Campos et al. 2004). Nevertheless, Mediterranean coastal areas are in general heavily invaded and under intensive human use, especially tourism-related activities (Chytrý et al. 2008b; Sobrino et al. 2009). Specifically, we ask: (i) Are patch and landscape characteristics more important than the regional degree of human influence or habitat type in explaining non-native species richness?, (ii) Which patch and landscape characteristics are the most relevant to non-native species richness? And finally, (iii) at what spatial extent does landscape characteristics have maximum influence on non-native species richness?

\section{Methods}

Study sites

The study was conducted in three administrative regions of Spain: Menorca Island, Girona, and Barcelona. The three regions were selected to represent a gradient from low to high human influence, respectively (Table 1). Menorca Island, declared Biosphere Reserve in 1993, belongs to the Balearic archipelago and it is located within the same latitude as the mainland regions. Balearic Islands are considered to be para-oceanic, as they were connected to the continent during the Messinian period (between 5.70 and 5.35 million years ago). Due to this pre-historical geographical connexion and the historical and current trade and transport between all these regions, they share an important component of both native and nonnative flora. The climate of the three regions is typically Mediterranean, with warm, dry summers and mild winters. They also share a similar cultural 
Table 1 Geographic characteristics of the three study regions

\begin{tabular}{llll}
\hline & \multicolumn{2}{l}{ Mainland } & \multicolumn{2}{l}{$\begin{array}{l}\text { Island } \\
\text { Menorca }\end{array}$} \\
\cline { 2 - 3 } & Barcelona & Girona & Menon \\
\hline Latitude (N) & $41.2-41.6$ & $41.7-42.4$ & $39.8-40.1$ \\
Longitude (E) & $1.7-2.8$ & $2.8-3.2$ & $3.8-4.2$ \\
Coast length $(\mathrm{km})$ & 187.7 & 332.9 & 432.5 \\
Population density & 4711.3 & 335.8 & 136.5 \\
$\quad\left(\text { hab } / \mathrm{km}^{2}\right)^{\mathrm{a}}$ & & & \\
Road length $\left(\mathrm{km} / \mathrm{km}^{2}\right)^{\mathrm{b}}$ & 2.52 & 2.94 & 1.33 \\
Urban area $\left(\mathrm{km}{ }^{2} / \mathrm{km}^{2}\right)^{\mathrm{b}}$ & 0.43 & 0.27 & 0.09 \\
Mean temperature & 16.3 & 15.9 & 16.8 \\
Mean precipitation & 636 & 609 & 608
\end{tabular}

${ }^{a}$ Coastal municipalities (Spanish National Statistics Institute 2011)

b Within 2,000 m coastal strips

landscape as a result of the typical interaction between man and environment at the Western Mediterranean region. Forests and shrublands dominate the hilly areas, as a result of agricultural land abandonment in the mid-twentieth century. In contrast, lowlands and coastal areas are intensively cultivated or urbanised.

\section{Floristic survey}

Non-native plant species (according to Bolós et al. 1993) were identified at the patch level in four types of coastal habitats: dunes (sand-covered shorelines), rock-outcrops (sea cliffs), shrublands (evergreen sclerophyllous shrub vegetation) and forests (pine/oak woodlands). The vegetation patches were selected from the most recent land-cover map for each region: the land-cover map of Catalonia (www.creaf.uab.cat/ mcsc, based on images from 2005) for Barcelona and Girona, and the land-cover map of Menorca (http:// www.obsam.cat/, based on images from 2002) for Menorca. These land-cover maps depict any distinct vegetation patch with a minimum area of $500 \mathrm{~m}^{2}$. First, we randomly selected an initial set of 50 patches of the land-cover maps for each habitat and study region with at least $60 \%$ of their area within a 500-m strip along the coast. Second, within this initial set, between 23 and 28 patches per habitat type and study region were selected to set up a gradient of patch area and human influence in the surroundings (percentage of urban and road area within $1 \mathrm{~km}$ radius). In Barcelona, we were able to sample only 16 rock-outcrop patches due to availability and accessibility constraints. Finally, a total of 295 patches ranging from 0.05 to 80 ha were sampled.

Patches were sampled from April to June 2010 depending on the regions, starting with the warmest (Menorca and southern Barcelona) and ending with the coldest (northern Barcelona and Girona). Within each region, patches were also sampled from south to north following the plant phenology. We performed an intensive prospection of each patch to identify all nonnative species growing therein. Prospection was done by three or more trained botanists walking through all its area with no time limit, to be reasonably sure that none non-native species was missed. Only neophytes (i.e. introduced after 1500AC) were considered. We did not consider archaeophytes (i.e. introduced before $1500_{\mathrm{AC}}$ ) due to the controversy of classifying some of them as native or non-native (Khadari et al. 2005). We then calculated non-native species richness per patch (i.e. total number of non-native species) as this is a good estimator of the level of plant invasion (Catford et al. 2011).

\section{Explanatory variables}

We characterized each patch with several patch and landscape variables (Table 2) commonly found to be associated to plant invasions at both grid and plot level (Deutschewitz et al. 2003; Pino et al. 2005; Ohlemüller et al. 2006; Kumar et al. 2006; Gavier-Pizarro et al. 2010). Patch and landscape variables were inferred from the most recent land-cover map for each region mentioned above. We calculated a set of patch variables, describing the geometry of the sampled patches; landscape composition variables, indicating the main land-cover categories; and landscape configuration variables, reflecting the arrangement of patches in the landscape surrounding the sampled patches (Table 2).

Patch variables included patch area, patch edge, and two shape complexity variables: patch shape index and patch fractal index. As composition variables we calculated the relative percentage of each land-cover type and three land-cover diversity indices: Shannon and Simpson indices and land-cover richness. Configuration variables have been rarely used in plant invasion studies. We selected two broadly used indices to quantify each of these relevant aspects: the amount of edge in the landscape (i.e. edge density and landscape shape index), the number and size of 
Table 2 Variables used as predictors of non-native species richness in coastal habitats with indication of the landscape extent (i.e. buffer area from the focal patch) selected

\begin{tabular}{|c|c|c|c|}
\hline Variable & $\begin{array}{l}\text { Extent } \\
(\mathrm{m})\end{array}$ & Description & Data source \\
\hline Habitat type & & $\begin{array}{l}\text { Four coastal habitats: dunes, rock- } \\
\text { outcrops, shrublands and forests }\end{array}$ & \\
\hline Region & & $\begin{array}{l}\text { Three regions to represent a gradient of } \\
\text { human influence: Barcelona, Girona } \\
\text { and Menorca }\end{array}$ & \\
\hline \multicolumn{4}{|l|}{ Patch characteristics } \\
\hline Patch edge (m) & & Perimeter of the focal patch & \multirow{4}{*}{$\begin{array}{l}\text { Land-cover map of Catalonia } 2005 \\
\text { (www.creaf.uab.cat/mcsc) and land-cover map } \\
\text { of Menorca } 2002 \text { (http://www.obsam.cat/) }\end{array}$} \\
\hline Patch area $(\mathrm{ha})^{\mathrm{a}}$ & & Area of the focal patch & \\
\hline Patch fractal index $(\operatorname{dim} .)^{a}$ & & $\begin{array}{l}\text { Two times the logarithm of the patch } \\
\text { perimeter divided by the logarithm of } \\
\text { patch area }\end{array}$ & \\
\hline Patch shape index (adim.) & & $\begin{array}{l}\text { Perimeter of the patch divided by the } \\
\text { minimum perimeter possible of a } \\
\text { circle of the corresponding patch area }\end{array}$ & \\
\hline \multicolumn{4}{|l|}{ Landscape composition } \\
\hline Natural land-cover $(\%)$ & & Forests, shrublands and open areas & \\
\hline Low-density urban land-cover $(\%)^{\mathrm{a}}$ & 100 & $\begin{array}{l}\text { Mixed garden and buildings areas such } \\
\text { as single-family housing areas and } \\
\text { touristy resorts }\end{array}$ & \\
\hline High-density urban land-cover $(\%)^{\mathrm{a}}$ & 100 & Built areas such as villages and cities & \\
\hline Agricultural land-cover $(\%)^{\mathrm{a}}$ & 100 & & \\
\hline Water land-cover $(\%)^{\mathrm{a}}$ & 100 & & \\
\hline \multicolumn{4}{|l|}{ Shannon land-cover diversity index } \\
\hline Simpson land-cover diversity index ${ }^{a}$ & 100 & & \\
\hline Land-cover richness & & $\begin{array}{l}\text { Number of land-cover types in the } \\
\text { landscape }\end{array}$ & \\
\hline \multicolumn{4}{|l|}{ Landscape configuration } \\
\hline Edge density $(\mathrm{m} / \mathrm{ha})^{\mathrm{a}}$ & 100 & $\begin{array}{l}\text { Total length of edge in the landscape } \\
\text { divided by the total landscape area }\end{array}$ & \\
\hline Patch density & & Number of patches in the landscape & \\
\hline Landscape shape index (adim.) & & $\begin{array}{l}\text { Total length of edge in the landscape } \\
\text { divided by the minimum total length } \\
\text { of edge possible }\end{array}$ & \\
\hline Mean patch area $(\mathrm{ha})^{\mathrm{a}}$ & 250 & $\begin{array}{l}\text { Mean area of all patches in the } \\
\text { landscape }\end{array}$ & \\
\hline Mean fractal index (adim.) ${ }^{\mathrm{a}}$ & 250 & $\begin{array}{l}\text { Mean fractal index of all patches in the } \\
\text { landscape }\end{array}$ & \\
\hline Mean shape index (adim.) & & $\begin{array}{l}\text { Mean shape index of all patches in the } \\
\text { landscape }\end{array}$ & \\
\hline Climate & & & WorldClim (Hijmans et al. 2005) \\
\hline \multicolumn{4}{|l|}{ Mean annual temperature $\left({ }^{\circ} \mathrm{C}\right)$} \\
\hline \multicolumn{4}{|c|}{ Mean minimum temperature $\left({ }^{\circ} \mathrm{C} \text { January }\right)^{\mathrm{a}}$} \\
\hline \multicolumn{4}{|l|}{ Mean maximum temperature $\left({ }^{\circ} \mathrm{C}\right.$ July) } \\
\hline \multicolumn{4}{|l|}{ Annual precipitation $(\mathrm{mm})^{\mathrm{a}}$} \\
\hline Mean annual radiation $\left(\mathrm{W} \mathrm{m}^{-2}\right)^{\mathrm{a}}$ & & & ASTER GDEM 2009 \\
\hline
\end{tabular}

dim dimensionless

a Variables included in the final analysis to avoid collinearity 
patches (i.e. patch density and mean patch area), and the mean patch-shape complexity (i.e. mean shape index and mean fractal index) (McGarigal et al. 2002).

We calculated configuration variables and landcover diversity indices using a land-cover map with the following classification: urban, natural, water, and agricultural. For the rest of variables regarding landscape composition we split the urban land-cover into low-density urban (i.e. mixed garden and buildings areas such as single-family housing areas and tourist resorts) and high-density urban (mainly builtup areas) as we were interested in the relative importance of both predictors. We calculated composition and configuration variables at five buffer distances (hereafter extent) from each sampled patch edge (100, 250, 500, 1,000 and 2,000 m) using ArcGIS 9.2 and FRAGSTATS (McGarigal et al. 2002).

Finally, to control for climate variability, we calculated several climate variables. For the centroid of each patch, we obtained mean annual temperature, mean minimum temperature in the coldest month (January), mean maximum temperature in the hottest month (July), and annual rainfall from the WorldClim dataset (Hijmans et al. 2005) at 30 arc-second resolution (approximately $1 \mathrm{Km}^{2}$ ). We calculated mean annual solar radiation at the centroid of each patch in GRASS based on the ASTER Global Digital Elevation Model (http://gdem.ersdac.jspacesystems. or.jp) of $30 \mathrm{~m}$ resolution.

\section{Statistical analyses}

We used variance-partition techniques (Mood 1969) and multimodel inference (Burnham and Anderson 2002) of generalized linear models (GLMs) to analyse the relationship between non-native species richness and region, landscape, habitat and patch variables. Climate variables were also included in the models as covariates to control their effect. We modelled the error terms of the GLMs using a negative binomial distribution, which is typically used for count data when overdispersion occurs (Gelman and Hill 2007).

Prior to both the partitioning and the multimodel inference modelling, for each landscape variable, we selected the extent that was most influential on nonnative species richness (Table 2). The selection was based on the Pearson's correlation coefficient between each landscape variable and non-native species richness at each buffer distance (Fig. 3). Then, we checked the collinearity among the selection of predictors by pair-wise Pearson's correlation tests (Supplementary Material 1). First, we selected variables that had a pairwise correlation lower than 0.6 and then selected the ones with best ecological meaning and explanatory power. With regard to patch variables, patch area was correlated with patch edge and patch shape index with the fractal index. For final models, we used the noncorrelated indices patch area and patch fractal index. Taking landscape composition variables into account, we found natural land-cover to be negatively correlated to urban land-cover and land-cover diversity. Thus, we kept high- and low-density urban land-cover, agricultural land-cover and water land-cover. The three land-cover diversity indices were correlated. We selected only the Simpson diversity index. Most landscape configuration variables were also highly correlated. We selected edge density, mean patch area and mean fractal index. Climate variables were highly correlated and thus we selected only mean annual precipitation, mean minimum temperature in the coldest month and mean annual solar radiation.

\section{Deviance partitioning}

Variance-partition techniques indicate the variability explained by the single and shared effects of different groups of variables (Mood 1969). Assuming that the deviance is a good measure of the variability explained by a model, we set up GLMs including a different subset of non-collinear variables: patch and landscape variables (i.e. including variables regarding patch geometry, landscape composition and landscape configuration), only regions, only habitat type, only climate variables and the combination of the four groups of variables. The deviance explained by each model was then used to identify the single and shared effects on non-native species richness by simple equation systems (Carrete et al. 2007). Following the same approach, we also partitioned the deviance of non-native species richness accounted by patch and landscape characteristics within patch geometry, composition and configuration variables.

\section{Multimodel inference}

Multimodel inference is a model selection method that allowed us to identify the best possible models and to rank all independent variables according to their 
influence on non-native species richness (Burnham and Anderson 2002). We performed multimodel inference based on the all-subsets selection of GLMs using Akaike's information criterion corrected for a large number of predictors (AICc).

We selected the best model (smallest AICc) for each block of non-collinear predictors (i.e. patch geometry, composition, configuration, and climate). Then, we repeated the procedure, combining the best variables of each block and the factors habitat type and region to establish the set of best candidate models. For each candidate model in the final selection, we calculated the Akaike weight of evidence $\left(\mathrm{w}_{\mathrm{i}}\right)$ to rank the predictors in order of importance (i.e. the closest to 1) in their relation to non-native species richness (Burnham and Anderson 2002; Grueber et al. 2011). The weight of evidence was calculated within the set of best models given the selected predictors: all models within four AICc units from the best model. This threshold is within the limits adopted in other studies (Grueber et al. 2011), and allowed the presence of all groups of variables.

Moreover, to avoid a possible correlation between the predictor and the response variable due to random or unexpected noise, we performed a permutation procedure (100 times) to calculate the unbiased weight of evidence $\left(\mathrm{Dw}_{+\mathrm{i}}\right)$ (Thuiller et al. 2007). Only predictors with $\mathrm{Dw}_{+\mathrm{i}}$ higher than zero had a certain explanatory power on the dependent variable (Thuiller et al. 2007).

We also used multimodel inference to estimate regression coefficients and their confident intervals (with the adjusted standard error) within the best models subset (delta <4) (Burnham and Anderson 2002; Burnham and Anderson 2004). We calculated the coefficient for a given predictor as the sum across all possible models where the predictor was present, of the predictor's coefficient multiplied by the $\mathrm{w}_{\mathrm{i}}$ (Burnham and Anderson 2002).

To explore the differences in non-native species richness among coastal habitat types and regions, we used the best candidate model (smallest AICc), including the factors habitat type and region. We tested significant differences among levels within each factor using a post hoc normal test with multiplicity correction by the joint distribution of all the statistics (Westfall 1997).

Due to the characteristics of the data and the generally aggregated pattern of plant invasions, it is very likely to find spatial autocorrelation in the residuals of the GLMs. Spatial autocorrelation could generate an underestimation of the confidence intervals in the regression coefficients. In preliminary analyses using the Moran's Index, we detected significant spatial autocorrelation in the model's residuals at distances smaller than 1,000 $\mathrm{m}$. Thus, for each GLM in the multimodel inference procedure we tested the spatial autocorrelation in the model's residuals by the Moran's index. When the spatial autocorrelation was proven to be significant $(p<0.05)$ we included a spatial autocovariate in the model considering the inverse distance among patches up to $1,000 \mathrm{~m}$ (Augustin et al. 1996; Dormann et al. 2007).

All statistical analyses were performed with the R-CRAN software (R Development Core Team 2009). We used the package MuMIn for some procedures of the multimodel inference method and the package VEGAN as the base code for deviance-partition.

\section{Results}

Differences on non-native species richness among regions and among habitat types

Across all the regions, we found 125 non-native species. The most abundant species were Carpobrotus edulis (L.) L. Bolus, Agave americana L., Pittosporum tobira (Thunb.) W.T. Ayton and Opuntia ficus-indica (L.) Mill., which occur in 31, 26, 24 and $23 \%$ of the patches, respectively.

Considering the best model that included habitat type and region (Supplementary Material 1), nonnative species richness of patches was significantly higher in the two mainland regions, Barcelona and Girona, than in Menorca Island (Fig. 1). However, we found no differences in non-native species richness between Barcelona and Girona. Invasion across coastal habitat types was significantly different (Fig. 1). Nonnative species richness was greater in forests than in rock-outcrops, while the richness of shrublands and dunes was not significantly different from those two.

Partitioning the influence of region, patch and landscape characteristics and habitat type on plant invasions

The variability of non-native species richness was explained mainly by patch and landscape variables, 
and by region (Fig. 2). Both sets of predictors also had a high shared effect. In contrast, habitat type had very low single effect and its explanatory power was shared mainly with patch, landscape and region variables (Fig. 2).

Considering patch and landscape variables separately, the deviance-partition analysis revealed that the composition of the landscape surrounding the patch explained most of the deviance (Fig. 2). Patch geometry and configuration variables showed very little single effect on non-native species richness and a similar amount was shared with composition variables.
Patch and landscape characteristics influencing plant invasions

The best patch and landscape predictors explaining non-native species richness were Simpson land-cover diversity index, percentage of agricultural land-cover, and mean fractal index (Table 3). Land-cover diversity showed a positive association with non-native species richness while the association with agricultural land-cover and mean fractal index was negative. Patch area, edge density and percentage of urban land-cover also had a significant positive effect on

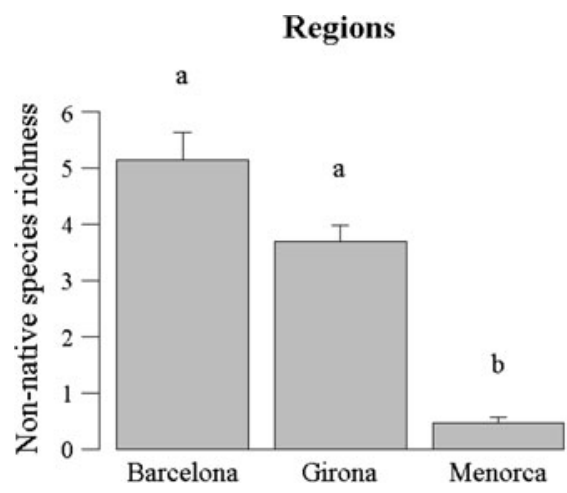

Fig. 1 Mean (+SE) non-native species richness for each region and habitat type. Letters indicate significant differences $(p<0.05)$ between regions and between habitats according to

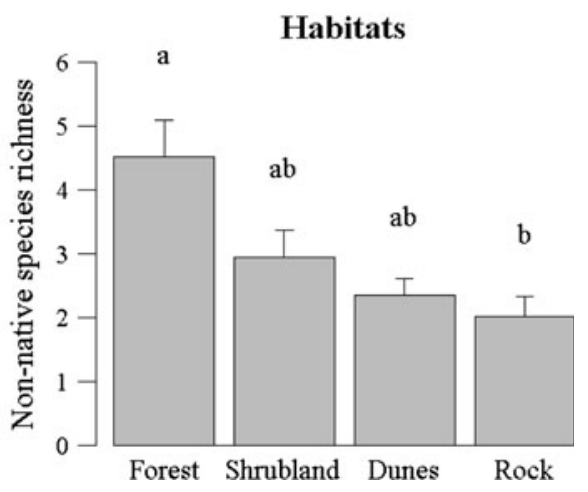

post hoc test corrected for multiple hypothesis based on the best model including habitat, region, landscape and climate variables selected by AICc criteria

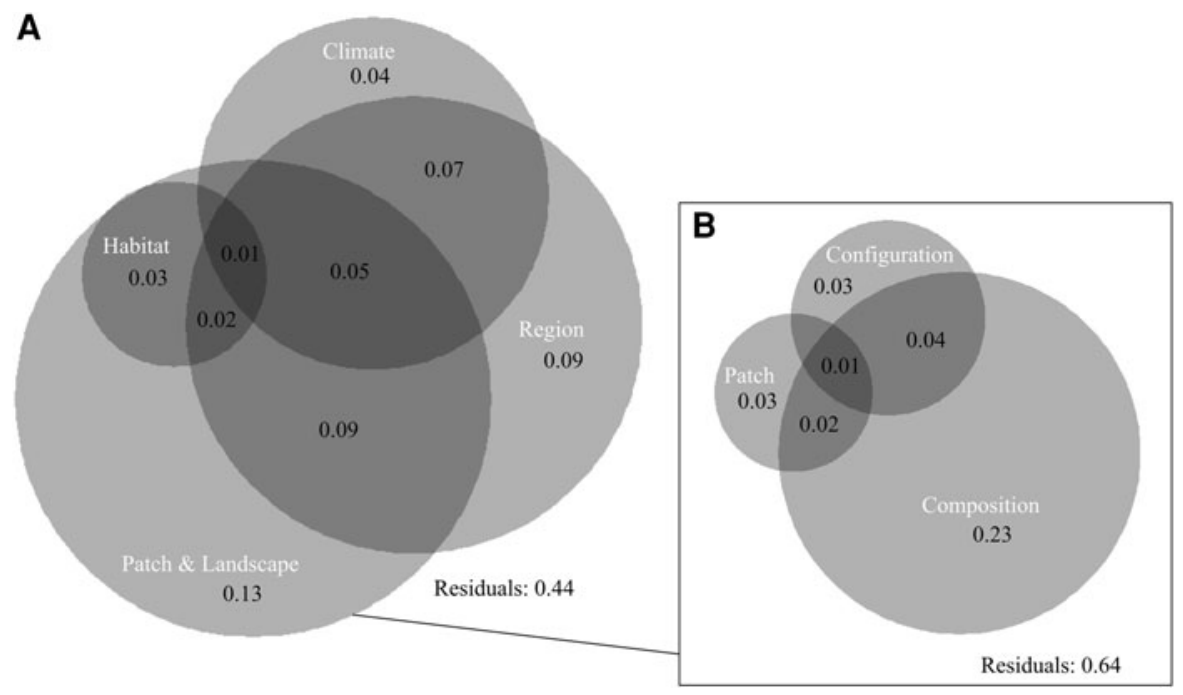

Fig. 2 Deviance partitioning of non-native species richness using generalized linear models among $\mathbf{A}$ region, climate, habitat type, and patch and landscape predictors, and $\mathbf{B}$ patch and landscape predictors: patch geometry, landscape composition, and landscape configuration. Each circle corresponds to a group of variables. Numbers within circles are the proportion of deviance explained by each set of predictors alone (nonoverlapped part of circles) or shared. Residuals indicate the deviance non-explained by the models 
non-native species richness. Regarding the percentage of urban land-cover, low-density urban land-cover showed higher importance than high-density landcover (Table 3).

The landscape extent relevant to plant invasions

Landscape composition and configuration variables showed different patterns of influence on non-native species richness, depending on the spatial extent. The most influential extent for landscape composition variables was $100 \mathrm{~m}$ around patches with a slight linear decrease in influence at larger radii (Fig. 3). By contrast, for configuration variables changes were more diverse (Fig. 3). A group of variables including mean shape complexity in the landscape (i.e. mean shape and fractal index) and patch density showed an unimodal response with maximum influence at 250-500 m. Edge density and landscape shape index showed a linear response. Landscape shape index and patch density had a positive effect on non-native species richness at smaller extents but changed to negative above $1,000 \mathrm{~m}$.

\section{Discussion}

The relative importance of patch and landscape characteristics influencing plant invasions

Plant invasions could be seen as a spatial hierarchical process where ecological factors affect invasions at different scales (McDonald and Urban 2006; Milbau et al. 2009). For instance, regional human influence and climate might control variability in non-native species richness at the regional scale (2,000-200 km), landscape characteristics might influence from the landscape to the local scale (200-1 km), while patch characteristics and habitat type influence invasion at the local scale. Following this hierarchical approach, we found patch and landscape characteristics the most important group of variables influencing non-native species richness in comparison to regional human influence and habitat type. The importance of landscape characteristics found is in line with the medium spatial scale of the study area $(<200 \mathrm{~km})$ (Milbau et al. 2009). Coarser scales such as continental, would probably found a more relevant role of climate

of region, habitat, patch, landscape (configuration and composition), and climate predictors for non-native species richness in Mediterranean coastal habitats
Table 3 Multimodel inference results: non-corrected and unbiased weight of evidence, averaged and standardized coefficient estimates $(\beta)$ and confidence intervals (95\% CI)

\begin{tabular}{|c|c|c|c|c|c|c|c|}
\hline Variable & Type & Weight & $\begin{array}{l}\text { Unbiased } \\
\text { weight }\end{array}$ & $\begin{array}{l}\beta \\
\text { Averaged }\end{array}$ & $\begin{array}{l}\text { Adjusted } \\
\text { SE }\end{array}$ & $\begin{array}{l}\text { Lower } \\
\text { CI }\end{array}$ & $\begin{array}{l}\text { Upper } \\
\text { CI }\end{array}$ \\
\hline Intercept & & & & 1.103 & 0.182 & 0.747 & 1.460 \\
\hline Spatial autocovariate & & & & 0.074 & 0.015 & 0.045 & 0.104 \\
\hline Region & Region & 1.000 & 0.820 & - & - & - & - \\
\hline Agricultural cover & Composition & 1.000 & 0.784 & -0.243 & 0.083 & -0.405 & -0.082 \\
\hline Patch area & Patch & 0.976 & 0.736 & 0.097 & 0.041 & 0.017 & 0.177 \\
\hline $\begin{array}{l}\text { Simpson land-cover diversity } \\
\text { index }\end{array}$ & Composition & 1.000 & 0.713 & 0.263 & 0.078 & 0.111 & 0.414 \\
\hline Mean fractal index & Configuration & 1.000 & 0.711 & -0.158 & 0.052 & -0.260 & -0.057 \\
\hline Edge density & Configuration & 0.856 & 0.645 & 0.148 & 0.068 & 0.014 & 0.282 \\
\hline Low-density urban cover & Composition & 0.790 & 0.591 & 0.117 & 0.057 & 0.006 & 0.227 \\
\hline High-density urban cover & Composition & 0.674 & 0.411 & 0.096 & 0.050 & -0.002 & 0.195 \\
\hline Habitat type & Habitat & 0.587 & 0.354 & - & - & - & - \\
\hline Patch fractal index & Patch & 0.457 & 0.243 & -0.083 & 0.057 & -0.194 & 0.028 \\
\hline Mean min. temperature & Climate & 0.231 & 0.015 & 0.110 & 0.126 & -0.138 & 0.357 \\
\hline
\end{tabular}

Predictors are sorted by importance according to the unbiased weight of evidence. Regression coefficients for the categorical variables habitat and region are not shown. Significant averaged coefficients are shown in bold. See Table 2 for a complete description of variables 


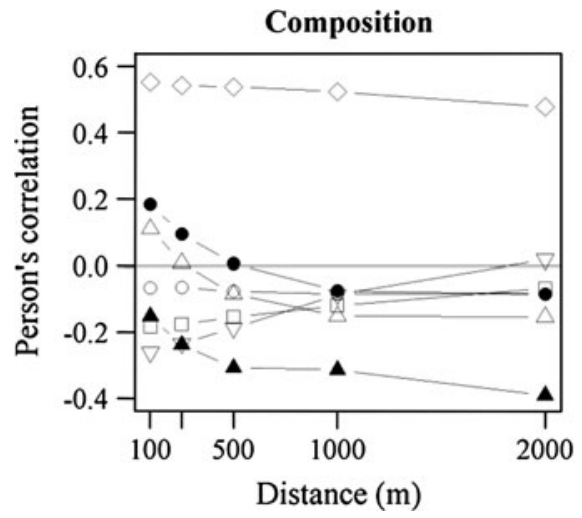

Fig. 3 Pearson's correlation coefficient between non-native species richness and landscape composition and configuration variables at each spatial extent $(100,250,500,1,000,2,000 \mathrm{~m}$ around sampled patch). For configuration variables, the landcover classification used considers urban, agricultural, natural and water land-covers. Composition: $\square$ agricultural land-cover,

(Pearson et al. 2004) or regional human influence. The effect of landscape variables is mainly related to an increased propagule pressure from fragmented human-altered areas (Chytrý, et al. 2008a; Catford et al. 2011; Vilà and Ibáñez 2011). Human-altered areas such as gardens, artificial edges or communication networks are usually heavily invaded (Vilà et al. 2007; Chytrý et al. 2008b) and can easily become the source of propagules to nearby natural areas.

The identity of the region was, after patch and landscape variables, the most important factor explaining non-native species richness in Mediterranean coastal habitats. Non-native species richness was higher in Barcelona and Girona regions than in the Menorca Island. This result was also found for a broader geographic area in Catalonia and Balearic regions using a regional database of vegetation relevés and it was attributed to the higher human influence in the mainland regions than in Menorca (Vilà et al. 2010). Stronger regional human influence could encompass factors known to increase non-native plant invasions such as higher propagule pressure from human-altered habitats and an intense use of nonnative plants for ornamental or restoration purposes (Simberloff 2009). Indeed, density of human population and that of road networks are larger in Catalonia than in the Balearic Islands (Vilà et al. 2010; Table 1). However, in Menorca, these effects might be confounded with insularity, which might alter the arrival and establishment of non-native plant species.

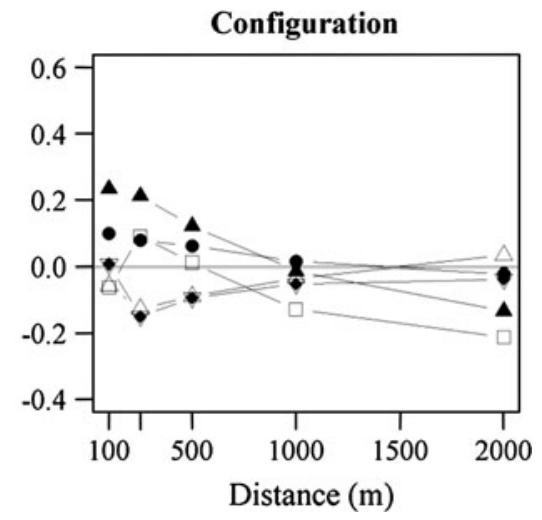

$\bigcirc$ water land-cover, $\nabla$ natural land-cover, $\diamond$ urban land-cover, $\Delta$ land-cover richness, $\triangle$ Shannon land-cover diversity, - Simpson land-cover diversity. Configuration: $\square$ patch density, edge density, $\boldsymbol{\Delta}$ landscape shape index, $\triangle$ mean patch area, $\nabla$ mean shape index, $\diamond$ mean fractal index

Classical works suggested that islands tend to be more heavily invaded than their mainland counterparts (Elton 1958; Lonsdale 1999; Pyšek and Richardson 2006). However, other studies confirm our findings supporting that communities in non-oceanic islands tend to be less invaded by non-native plants than in the mainland (Teo et al. 2003; Atwood and Meyerson 2011). Furthermore, even when islands were found to be more invaded these differences could be explained by other factors not directly linked to insularity, but to differences in anthropic disturbances (Yiming et al. 2006). Thus, after accounting for landscape characteristics and climate differences, our results suggest that the difference in regional human influence is the most important aspect explaining the differences in plant invasions across regions. Other factors not explored in this study that could account for difference in invasion might be related to differences in invasion history (Teo et al. 2003; Yiming et al. 2006; Vilà et al. 2010). However, its relative importance should be considered rather low due to the intensive trade and transport among regions.

Although we found significant differences among habitats, habitat type alone did not explain a high amount of deviance in non-native species richness. On the contrary, previous studies have found habitat type to be the foremost factor explaining differences in plant invasions (Chytrý et al. 2008a; Gassó et al. 2012). One reason for this discrepancy could be the environmental similarity among the habitats assessed 
in our study. Furthermore, habitat type encompasses a range of factors known to affect plant invasions (Chytrý et al. 2009; Catford et al. 2011). The partition analyses revealed that habitat type shared its explained deviance with landscape, region and climatic variables. Therefore, although habitat type might not be the most important predictor, it might be used as a simple estimate of invasion risk when information on the landscape or climate is scarce.

Patch and landscape characteristics influencing plant invasions

Landscape composition variables were more important predictors of non-native species richness than landscape configuration or patch variables. The importance of landscape composition on plant invasions has been widely confirmed in many studies (Vilà and Ibáñez 2011). Land-cover diversity and the percentage of urban and agricultural land-cover were the most important landscape predictors of non-native species richness. Highly diverse landscapes support the idea that a larger gradient of environmental conditions allows the establishment and spread of many different non-native species. In turn, these landscapes could provide a greater pool of non-native species with the potential to reach natural vegetation patches (Pino et al. 2005; Marini et al. 2009).

Urban land-cover usually has a positive effect on plant invasion both at plot and grid level (Pino et al. 2005; Gassó et al. 2009; Gavier-Pizarro et al. 2010; Vilà and Ibáñez 2011). However, not all urban areas contribute the same to plant invasion. Patches surrounded by low-density urban areas showed higher non-native species richness than high-density urban areas. These results support previous findings by Gavier-Pizarro et al. (2010) within administrative regions in New England (USA). The low-density urban land-cover is characterized by fragmented and disturbed natural areas within a loose matrix of gardening and housing areas. Therefore, the probability of non-native ornamental species spreading from gardening and housing areas into adjacent natural areas is higher in a low-density urban landscape matrix.

Agricultural land-cover was negatively associated with non-native species richness, as found in other studies (Ibáñez et al. 2009; Marini et al. 2009). The effect of agricultural land-cover depends on the surrounding landscape and habitat type (Vilà and Ibáñez 2011). In human-influenced landscapes, as in our study, agriculture could act as a buffer against invasion. Especially in forests, where invasion into the interior is driven mainly by shade-tolerant ornamental species, agriculture areas could act as a barrier to their expansion (Cadenasso and Pickett 2001). Furthermore, non-native species of agricultural origin may not invade natural areas but remain as weeds in crops (Vilà et al. 2004).

The effect of landscape configuration and patch characteristics on plant invasions has been traditionally less explored (Vilà and Ibáñez 2011). The low importance of these variables found in contrast to landscape composition variables underpins their idiosyncratic effects on plant invasions. As in previous works by Kumar et al. (2006) and Bartuszevige et al. (2006), we found that patches surrounded by fragmented landscapes (i.e. high edge density) underwent heavier invasions. Edges are usually highly invaded and thus might play an important role both as sources and sinks of non-native propagules (Vilà and Ibáñez 2011). Mean landscape-shape complexity (i.e. mean fractal index) had a negative association with nonnative plant richness. To our knowledge, the only study available exploring this attribute found a positive association (Kumar et al. 2006). Our opposite finding might be explained by less shape complexity of anthropogenic landscapes (mainly urban and agricultural) than natural landscapes. In fact, there was a negative correlation between mean shape complexity and urban land-cover (Supplementary Material 1).

Finally, the only patch characteristic influencing non-native species richness was patch area. The positive relationship found between patch size and non-native species richness might be simply trivial (i.e. the larger patch area the more opportunities for random establishment of non-native species), but it might also reflect higher microhabitat diversity of large patches compared with that of small ones. This finding contradicts previous studies where the relationship was not significant (Cully et al. 2003) or even negative (Ohlemüller et al. 2006; Guirado et al. 2006). The lack of effect of patch shape complexity is in line with other studies (Bartuszevige et al. 2006; Vilà and Ibáñez 2011; but see Ohlemüller et al. 2006). These results confirm the variability of the influence of patch characteristics on non-native species richness in 
comparison to propagule pressure proxies such as landscape composition variables.

The landscape extent relevant to plant invasions

We found high variability in the association of landscape characteristics with non-native species richness considering the spatial extent of study. The sensitivity of landscape indices to the spatial extent is a major concern when trying to elucidate the importance of landscape characteristics in ecological processes (Baldwin et al. 2004; Kumar et al. 2006; Bailey et al. 2007). While previous studies have found $250 \mathrm{~m}$ to be the most influential extent in plant invasions (Sullivan et al. 2005; Kumar et al. 2006; Bartuszevige et al. 2006), our findings suggest that the major influence occurs at smaller spatial extents $(100 \mathrm{~m})$ for most of the variables. In highly altered systems such as in our study area, the immediate neighbouring space is probably the most relevant extent to invasion because it might reflect a direct link with disturbance and species dispersal. For example, adjacent urban areas might facilitate the arrival of ornamental plant species without the need of long-distance dispersal events or an increase in human frequentation.

We also found that landscape configuration variables caused more diverse changes across spatial extents than did landscape composition variables. While composition variables showed slightly linear decrease in association, most of the configuration variables showed also unimodal responses to the extent (i.e. maximum association at 200-250 m). This finding reinforces the idiosyncratic effect of landscape configuration variables on non-native species richness, and the importance of performing sensitivity analyses to detect the most relevant landscape extent for each landscape predictor (Kumar et al. 2006). Other aspects on the sensitivity of landscape indices not explored in this study that might require further research are the type of landscape (e.g. urban vs. agriculture landscapes), the landscape thematic resolution (i.e. classification scheme of land-cover types) and the sampling resolution (Baldwin et al. 2004; Kumar et al. 2006).

\section{Conclusions}

Landscape composition was the most important determinant of non-native plant invasions in Mediterranean coastal areas. Natural areas close to diverse and urban landscapes are highly vulnerable to plant invasions while surrounding agricultural areas could buffer this effect. Within highly invaded systems the effect of landscape composition is clearly more evident than the variability in regional human influence, habitat type, patch geometry or landscape configuration. The prevalence of this pattern might also depend on the range of climatic conditions, habitat similarity and the stage of invasion under consideration. Thus, our findings indicate that invasion-risk analyses must take into account the landscape matrix, especially in terms of land-cover diversity and human alteration (Hulme 2006).

Our study also advocates that plant-invasion risk analyses considering landscape characteristics should include sensitivity analyses in order to test differences across spatial extents (Kumar et al. 2006; Pauchard and Shea 2006). Our study yielded a wide variability in the strength of association of landscape variables with non-natives species richness at different spatial extents. Thus, a measure of landscape characteristics at a single spatial extent might lead to erroneous conclusions about the susceptibility of an area to invasion. Once the spatial extent that maximizes plant invasions is identified, it could be used to target the management of non-native species. Usually, the management of non-native species focus on the stand scale (Pauchard and Shea 2006) although other approaches have been applied at the landscape scale (e.g. vehicles or weed cleaning) or even at broader scales (e.g. import regulation). Our study suggests that management of the neighbouring landscape (i.e. $100-250 \mathrm{~m}$ ) should be a priority to control plant invasions at the local scale.

Acknowledgments We thank comments from two anonymous referees to a previous version of this manuscript. Research was funded by the Spanish Ministerio de Ciencia e Innovación projects Consolider-Ingenio MONTES (CSD2008-00040), RIXFUTUR (CGL2009-7515) and the Junta de Andalucía project RNM-4031.

\section{References}

Atwood JP, Meyerson LA (2011) Island biogeography extends to small-scale habitats: low competitor density and richness on islands may drive trait variation in nonnative plants. Biol Invasions 13:2035-2043

Augustin NH, Mugglestone MA, Buckland ST (1996) An autologistic model for the spatial distribution of wildlife. J Appl Ecol 33:339-347 
Bailey D, Billeter R, Aviron S, Schweiger O, Herzog F (2007) The influence of thematic resolution on metric selection for biodiversity monitoring in agricultural landscapes. Landscape Ecol 22:461-473

Baldwin DJB, Weaver K, Schnekenburger F, Perera AH (2004) Sensitivity of landscape pattern indices to input data characteristics on real landscapes: implications for their use in natural disturbance emulation. Landscape Ecol 19:255-271

Bartuszevige AM, Gorchov DL, Raab L (2006) The relative importance of landscape and community features in the invasion of an exotic shrub in a fragmented landscape. Ecography 29:213-222

Bolós O, Vigo J, Masalles RM, Ninot JM (1993) Flora Manual dels Països Catalans, 2nd edn. Pòrtic, Barcelona, Spain

Burnham KP, Anderson DR (2002) Model selection and multimodel inference: a practical information-theoretic approach, 2nd edn. Springer, New York, USA

Burnham KP, Anderson DR (2004) Multimodel inference: understanding AIC and BIC in model selection. Sociol Methods Res 33:261-304

Cadenasso ML, Pickett STA (2001) Effect of edge structure on the flux of species into forest interiors. Conserv Biol 15:91-97

Campos JA, Herrera M, Biurrun I, Loidi J (2004) The role of alien plants in the natural coastal vegetation in centralnorthern Spain. Biodivers Conserv 13:2275-2293

Carrete M, Grande JM, Tella JL, Sánchez-Zapata JA, Donázar JA, Díaz-Delgado R, Romo A (2007) Habitat, human pressure, and social behavior: partialling out factors affecting large-scale territory extinction in an endangered vulture. Biol Conserv 136:143-154

Catford JA, Vesk PA, White MD, Wintle BA (2011) Hotspots of plant invasion predicted by propagule pressure and ecosystem characteristics. Divers Distrib 17:1099-1110

Chytrý M, Jarošík V, Pyšek P, Hájek O, Knollová I, Tichý L, Danihelka J (2008a) Separating habitat invasibility by alien plants from the actual level of invasion. Ecology 89: $1541-1553$

Chytrý M, Maskell LC, Pino J, Pyšek P, Vilà M, Font X, Smart SM (2008b) Habitat invasions by alien plants: a quantitative comparison among Mediterranean, subcontinental and oceanic regions of Europe. J Appl Ecol 45:448-458

Chytrý M, Pyšek P, Wild J, Pino J, Maskell LC, Vilà M (2009) European map of alien plant invasions based on the quantitative assessment across habitats. Divers Distrib 15:98-107

Cully AC, Cully JF, Hiebert RD (2003) Invasion of exotic plant species in tallgrass prairie fragments. Conserv Biol 17:990-998

Deutschewitz K, Lausch A, Kühn I, Klotz S (2003) Native and alien plant species richness in relation to spatial heterogeneity on a regional scale in Germany. Global Ecol Biogeogr 12:299-311

Dormann C, McPherson JM, Araújo MB, Bivand R, Bolliger J, Carl G, Davies RG, Hirzel A, Jetz W, Daniel Kissling W, Kühn I, Ohlemüller R, Peres-Neto PR, Reineking B, Schröder B, Schurr MF, Wilson R (2007) Methods to account for spatial autocorrelation in the analysis of species distributional data: a review. Ecography 30:609-628
Elton C (1958) The ecology of invasions by animals and plants. Chapman \& Hall, London, UK

Gassó N, Sol D, Pino J, Dana ED, Lloret F, Sanz-Elorza M, Sobrino E, Vilà M (2009) Exploring species attributes and site characteristics to assess plant invasions in Spain. Divers Distrib 15:50-58

Gassó N, Pino J, Font X, Vilà M (2012) Regional context affects native and alien plant species richness across habitat types. App Veg Sci 15:4-13

Gavier-Pizarro GI, Radeloff VC, Stewart SI, Huebner CD, Keuler NS (2010) Housing is positively associated with invasive exotic plant species richness in New England, USA. Ecol Appl 20:1913-1925

Gelman A, Hill J (2007) Data analysis using regression and multilevel/hierarchical models, 1st edn. Cambridge University Press, New York, USA

Grueber CE, Nakagawa S, Laws RJ, Jamieson IG (2011) Multimodel inference in ecology and evolution: challenges and solutions. J Evol Biol 24:699-711

Guirado M, Pino J, Roda F (2006) Understorey plant species richness and composition in metropolitan forest archipelagos: effects of forest size, adjacent land use and distance to the edge. Global Ecol Biogeogr 15:50-62

Hijmans RJ, Cameron SE, Parra JL, Jones PG, Jarvis A (2005) Very high resolution interpolated climate surfaces for global land areas. Int J Climatol 25:1965-1978

Hulme PE (2006) Beyond control: wider implications for the management of biological invasions. J Appl Ecol 43:835847

Ibáñez I, Silander JA Jr, Allen JM, Treanor SA, Wilson A (2009) Identifying hotspots for plant invasions and forecasting focal points of further spread. J Appl Ecol 46:1219-1228

Khadari B, Grout C, Santoni S, Kjellberg F (2005) Contrasted genetic diversity and differentiation among Mediterranean populations of Ficus carica L.: a study using mtDNA RFLP. Genet Resour Crop Evol 52:97-109

Kueffer C, Daehler CC, Torres-Santana CW, Lavergne C, Meyer JY, Otto R, Silva L (2010) A global comparison of plant invasions on oceanic islands. Perspect Plant Ecol 12:145-161

Kumar S, Stohlgren TJ, Chong GW (2006) Spatial heterogeneity influences native and nonnative plant species richness. Ecology 87:3186-3199

Lonsdale WM (1999) Global patterns of plant invasions and the concept of invasibility. Ecology 80:1522-1536

Marini L, Gaston KJ, Prosser F, Hulme PE (2009) Contrasting response of native and alien plant species richness to environmental energy and human impact along alpine elevation gradients. Global Ecol Biogeogr 18:652-661

McDonald RI, Urban DL (2006) Edge effects on species composition and exotic species abundance in the North Carolina Piedmont. Biol Invasions 8:1049-1060

McGarigal K, Neel MC, Ene E (2002) FRAGSTATS 3.3: spatial pattern analysis program for categorical maps. Computer software program. University of Massachusetts Amherst

Milbau A, Stout JC, Graae BJ, Nijs I (2009) A hierarchical framework for integrating invasibility experiments incorporating different factors and spatial scales. Biol Invasions 11:941-950

Mood AM (1969) Macro-analysis of the American educational system. Oper Res 17:770-784 
Ohlemüller R, Walker S, Bastow Wilson J (2006) Local vs regional factors as determinants of the invasibility of indigenous forest fragments by alien plant species. Oikos 112:493-501

Pauchard A, Shea K (2006) Integrating the study of non-native plant invasions across spatial scales. Biol Invasions 8:399-413

Pearson RG, Dawson TP, Liu C (2004) Modelling species distributions in Britain: a hierarchical integration of climate and land-cover data. Ecography 27:285-298

Pino J, Font X, Carbó J, Jové M, Pallarès L (2005) Large-scale correlates of alien plant invasion in Catalonia (NE of Spain). Biol Conserv 122:339-350

Pyšek P, Richardson DM (2006) The biogeography of naturalization in alien plants. J Biogeogr 33:2040-2050

Pyšek P, Jarošík V, Hulme PE, Kühn I, Wild J, Arianoutsou M, Bacher S, Chiron F, Didžiulis V, Essl F, Genovesi P, Gherardi F, Hejda M, Kark S, Lambdon PW, DesprezLoustau M-L, Nentwig W, Pergl J, Poboljšaj K, Rabitsch W, Roques A, Roy DB, Shirley S, Solarz W, Vilà M, Winter M (2010) Disentangling the role of environmental and human pressures on biological invasions across Europe. Proc Natl Acad Sci USA 107(27):12157-12162

R Development Core Team (2009) R: a language and environment for statistical computing, version 2.9.2. Foundation for Statistical Computing, Vienna, Austria

Simberloff D (2009) The role of propagule pressure in biological invasions. Annu Rev Ecol Syst 40:81-102

Sobrino E, Sanz-Elorza M, Dana ED, González-Moreno A (2009) Invasibility of a coastal strip in NE Spain by alien plants. J Veg Sci 13:585-594
Steffan-Dewenter I, Münzenberg U, Tscharntke T (2001) Pollination, seed set and seed predation on a landscape scale. Proc R Soc Lond B 268:1685-1690

Sullivan JJ, Timmins SM, Williams PA (2005) Movement of exotic plants into coastal native forests from gardens in northern New Zealand. New Zeal J Ecol 29:1-10

Teo DHL, Tan HTW, Corlett RT, Wong CM, Lum SKY (2003) Continental rain forest fragments in Singapore resist invasion by exotic plants. J Biogeogr 30:305-310

Thuiller W, Slingsby JA, Privett SDJ, Cowling RM (2007) Stochastic species turnover and stable coexistence in a species-rich, fire-prone plant community. PLoS One 2:e938

Vilà M, Ibáñez I (2011) Plant invasions in the landscape. Landscape Ecol 26:461-472

Vilà M, Williamson M, Lonsdale M (2004) Competition experiments on alien weeds with crops: lessons for measuring plant invasion impact? Biol Invasions 6:59-69

Vilà M, Pino J, Font X (2007) Regional assessment of plant invasions across different habitat types. J Veg Sci 18:35-42

Vilà M, Pino J, Montero A, Font X (2010) Are island plant communities more invaded than their mainland counterparts? J Veg Sci 21:438-446

Westfall PH (1997) Multiple testing of general contrasts using logical constraints and correlations. J Am Stat Assoc 92:299-306

Yiming L, Zhengjun W, Duncan RP (2006) Why islands are easier to invade: human influences on bullfrog invasion in the Zhoushan archipelago and neighboring mainland China. Oecologia 148:129-136 